\title{
Material Properties of Titanium Diboride
}

\section{Ronald G. Munro}

National Institute of Standards and Technology, Gaithersburg, MD 20899-8520

ronald.munro@nist.gov
The physical, mechanical, and thermal properties of polycrystalline $\mathrm{TiB}_{2}$ are examined with an emphasis on the significant dependence of the properties on the density and grain size of the material specimens. Using trend analysis, property relations, and interpolation methods, a coherent set of trend values for the properties of polycrystalline $\mathrm{TiB}_{2}$ is determined for a mass fraction of $\mathrm{TiB}_{2} \geqslant 98 \%$, a density of $(4.5 \pm 0.1) \mathrm{g} / \mathrm{cm}^{3}$, and a mean grain size of $(9 \pm 1) \mu \mathrm{m}$.
Key words: evaluated data; material properties; mechanical properties; physical properties; thermal properties; titanium diboride .

Accepted: July 21, 2000

Available online: http://www.nist.gov/jres

\section{Introduction}

Titanium diboride $\left(\mathrm{TiB}_{2}\right)$ is well known as a ceramic material with relatively high strength and durability as characterized by the relatively high values of its melting point, hardness, strength to density ratio, and wear resistance [1]. Current use of this material, however, appears to be limited to specialized applications in such areas as impact resistant armor, cutting tools, crucibles, and wear resistant coatings. An important evolving application is the use of $\mathrm{TiB}_{2}$ cathodes in the electrochemical reduction of alumina to aluminum metal. Other applications may develop rapidly if the electrical discharge machining of $\mathrm{TiB}_{2}$ can be perfected. Broader application of this material may be inhibited by economic factors, particularly the cost of densifying a material with a high melting point, and concerns about the variability of the material properties. The present paper addresses the latter issue by examining the physical, mechanical, and thermal properties of $\mathrm{TiB}_{2}$ as a function of density and grain size.

This work extends the approach to data evaluation begun in previous studies on alumina [2] and silicon carbide [3]. The latter studies had a significant advantage over the present one, namely that the processing procedures were sufficiently well refined that batch to batch variations in the properties could be relatively small. For titanium diboride, the processing procedures do not seem to be as highly refined, and consequently, one must anticipate greater batch to batch variability. Therefore, it is all the more important to have a coherent view of the properties of $\mathrm{TiB}_{2}$ and their dependence on microstructure. The present work constructs such a view in the context of trends of property values. 
The bane of all ceramic materials is that a particular measured property value for a particular specimen may depend on a particular feature of the particular microstructure of that particular specimen. In the absence of tightly controlled processing procedures, the best that one can do as a means of generically characterizing such a material is to establish trends of values that occur in correlation with changes in the microstructure and composition. Given such trends, it should then be possible to interpolate to a set of property values for a single constrained composition and microstructure such that the set is consistent both with respect to the trends and with respect to known mutual property relations. Fortunately, the trend of the value of a property across a range of microstructures depends on the statistical characterization of the microstructure. Therefore, the trend of a property value may have a discernable correlation with one or more statistics of the microstructure, such as mean grain size, mean pore size, or bulk density. This approach is applied here to the properties of $\mathrm{TiB}_{2}$.

\section{Material Description}

Single crystal $\mathrm{TiB}_{2}$ exhibits hexagonal symmetry, Fig. 1 with space group $\mathrm{P} 6 / \mathrm{mmm}$. The lattice parameters [4-7], Fig. 2, have a slight quadratic dependence on the temperature which accounts for the linear temperature dependence of the coefficient of thermal expansion. The ratio $c / a$ ranges from $(1.066 \pm 0.001)$ at $25^{\circ} \mathrm{C}$ to $(1.070 \pm 0.001)$ at $1500{ }^{\circ} \mathrm{C}$. Individually, the lattice parameters may be expressed as

$a / \AA ̊=3.0236+1.73 \times 10^{-5}(T / \mathrm{K})+3.76 \times 10^{-9}(T / \mathrm{K})^{2}$

$c / \AA ̊=3.2204+2.73 \times 10^{-5}(T / \mathrm{K})+3.95 \times 10^{-9}(T / \mathrm{K})^{2}$

where $293 \mathrm{~K} \leq T \leq 2000 \mathrm{~K}$, and the relative standard uncertainties [8] $u_{\mathrm{r}}(a)=0.03 \%$ and $u_{\mathrm{r}}(c)=0.04 \%$ are estimated from the variances of the least-squares fits. Using the molar mass $M=69.522 \mathrm{~g} / \mathrm{mol}$ and the volume of the hexagonal unit cell $V=(3 / 4)^{1 / 2} a^{2} c$, the density $\rho_{\text {xtal }}$ of the single crystal can be calculated as

$$
\rho_{\text {xtal }}=\frac{M z}{N_{\mathrm{A}} V},
$$

where $z=1$ is the number of formula units per unit cell, and $N_{\mathrm{A}}$ is the Avogadro constant. At $20^{\circ} \mathrm{C}$, $\rho_{\text {xtal }}=(4.500 \pm 0.0032) \mathrm{g} / \mathrm{cm}^{3}$. The relative standard uncertainty $u_{\mathrm{r}}\left(\rho_{\text {xtal }}\right)$ is calculated as a propagation of uncertainty from the measured values of $a$ and $c$; viz.

$u_{\mathrm{r}}\left(\rho_{\text {xtal }}\right)^{2}=u_{\mathrm{r}}(V)^{2}=4 u_{\mathrm{r}}(a)^{2}+u_{\mathrm{r}}(c)^{2}=5.2 \times 10^{-7}$.

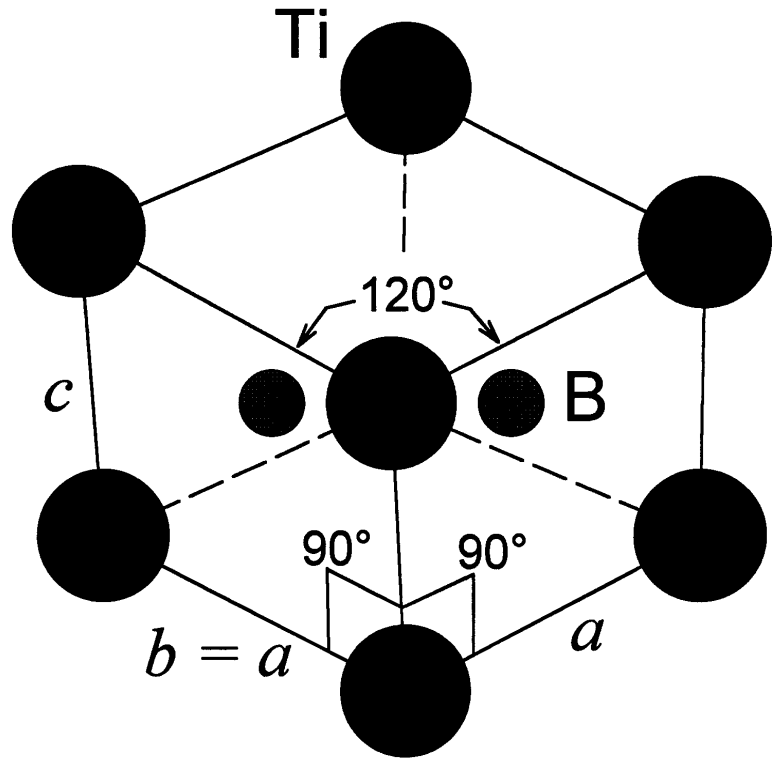

Fig. 1. The hexagonal unit cell of single crystal $\mathrm{TiB}_{2}$, space group $\mathrm{P} 6 / \mathrm{mmm}, a=b \neq c, \alpha=\beta=90^{\circ}, \gamma=120^{\circ}, 1$ formula unit per cell, Ti at $(0,0,0), \mathrm{B}$ at $(1 / 3,2 / 3,1 / 2)$ and $(2 / 3,1 / 3,1 / 2)$.

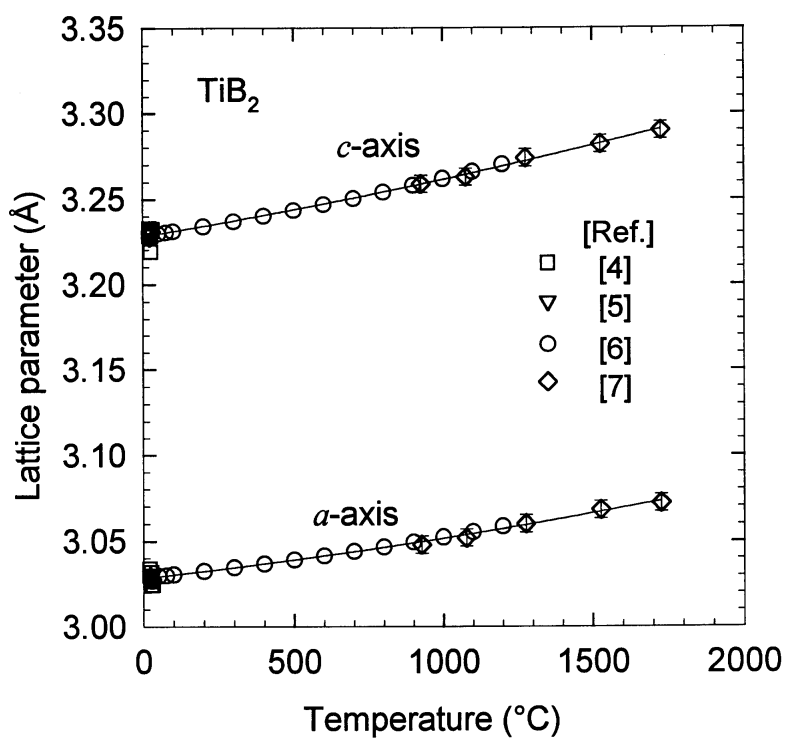

Fig. 2. Lattice parameters $a$ and $c$ of single crystal $\mathrm{TiB}_{2}$ as a function of temperature.

Nearly fully dense polycrystalline $\mathrm{TiB}_{2}$ can be produced by a variety of processing methods, including sintering [9-13], hot pressing [14], hot isostatic pressing $[10,11,15,16]$, microwave sintering [17], and dynamic compaction [18]. The relatively strong covalent bonding of the constituents, however, results in low selfdiffusion rates. Consequently, given also a high melting point of 
$(3225 \pm 20){ }^{\circ} \mathrm{C}$ [19-21], pressureless sintering of $\mathrm{TiB}_{2}$ requires a relatively high sintering temperature, on the order of $2000{ }^{\circ} \mathrm{C}$. Unfortunately, grain growth is also accelerated by the higher temperature, and the anisotropy of the hexagonal grain structure results in deleterious internal stresses and the onset of spontaneous microcracking during cooling. Grain growth can be limited and densification enhanced by the use of sintering aids such as $\mathrm{Cr}, \mathrm{CrB}_{2}, \mathrm{C}, \mathrm{Ni}, \mathrm{NiB}$, and $\mathrm{Fe}$. The solubility of $\mathrm{TiB}_{2}$ in liquid $\mathrm{Ni}$ and $\mathrm{Fe}$ appears to be especially useful in this regard. In such cases, the mass fraction of the sintering aid in the specimen may range from $1 \%$ to $10 \%$, while the sintering temperature may be reduced to the range of $1700{ }^{\circ} \mathrm{C}$ to $1800{ }^{\circ} \mathrm{C}$ for sintering times on the order of $1 \mathrm{~h}$. Successful hot pressing with $\mathrm{Ni}$ additives can be achieved with a hot pressing temperature as low as $1425^{\circ} \mathrm{C}$ with a sintering time of $2 \mathrm{~h}$ to $8 \mathrm{~h}$ [14]. When sintering aids are used in the composition, the theoretical maximum density, $\rho_{\text {theo }}$, can be different from the density of the pure crystal, $\rho_{\text {xtal }}$, because of the differing mass density of the sintering aid and the influence of the sintering aid on the lattice parameters.

\section{Mechanical and Thermal Properties}

The diversity of the processing conditions is a significant factor in the often widely varying property values reported in the literature for polycrystalline $\mathrm{TiB}_{2}$. In this section, the availiable mechanical and thermal properties are examined with the intent of providing a better understanding of how the properties depend on the composition, grain size, and density of the material.

\subsection{Elastic Moduli}

For isotropic polycrystalline materials, the elastic properties may be expressed in terms of two independent moduli, the elastic modulus $E$ and the shear modulus $G$. Values of $E[18,22-26]$ determined at room temperature by ultrasonic velocity and resonance methods for various grain sizes and densities fall roughly into two groups that are distinguished by density, but which have little perceptible dependence on grain size. This observation is consistent with numerous models that consider elastic properties to vary principally as a function of porosity. Over a large range of porosity (as much as $50 \%$ ), the dependence is well described by an exponential model [27], $E=E_{\mathrm{s}} \mathrm{e}^{-b \phi}$, although for lower degrees of densification the modulus decreases more rapidly [28]. In this expression, $E_{\mathrm{s}}$ and $b$ are parameters, and $\phi$ is the volume fraction of porosity. For a wide variety of ceramics [29], $b \approx 4.1 \pm 1.8$. Hence, for porosity that is less than about $10 \%$, expanding the exponential to first order in $\phi$ yields $E \approx E_{\mathrm{s}}{ }^{\prime}+b^{\prime} \rho$ using $\phi=1-\rho / \rho_{\text {theo }}$ for total porosity and setting $E_{\mathrm{s}}{ }^{\prime}=E_{\mathrm{s}}(1-b)$ and $b^{\prime}=E_{\mathrm{s}} b / \rho_{\text {theo }}$. Consequently, it can be expected that the elastic modulus will be linear in the measured density.

Neglecting any effect of the grain size in this case, Figs. 3 and 4 [14,18, 22-25, 30-33] show, respectively, that $E$ has a significant dependence on both the density

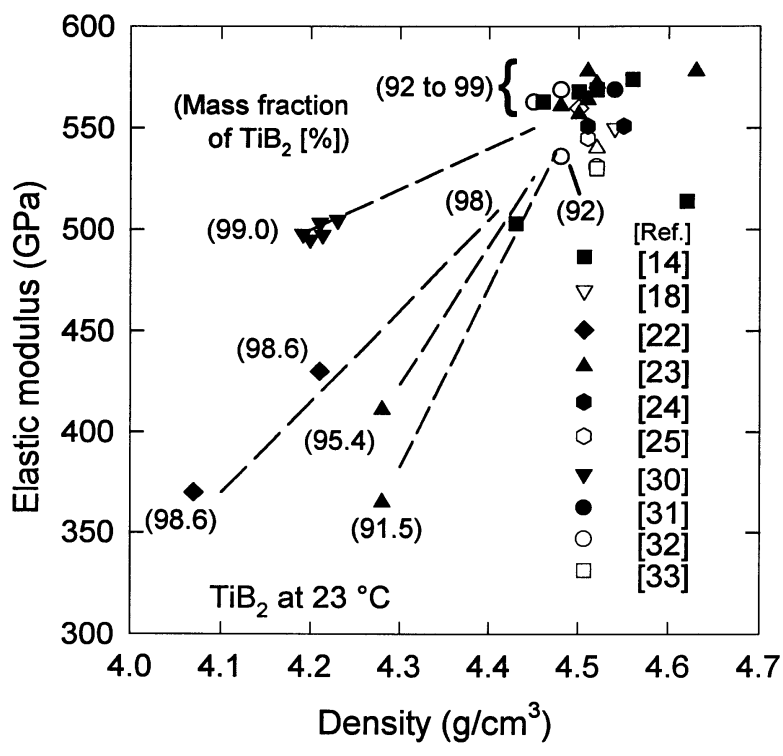

Fig. 3. The elastic modulus of $\mathrm{TiB}_{2}$ at room temperature as a function of density.

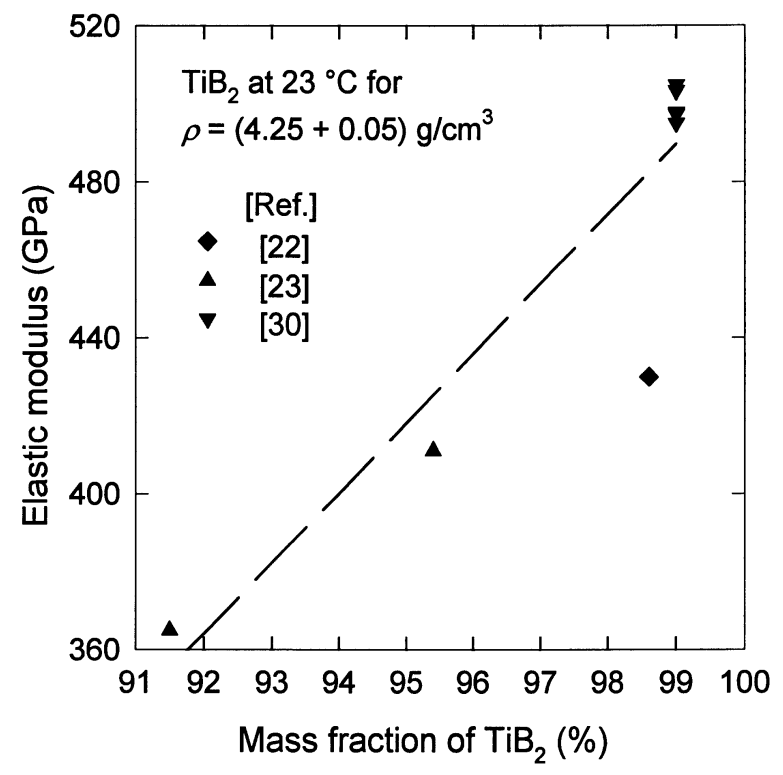

Fig. 4. The significant increase in the elastic modulus of $\mathrm{TiB}_{2}$ with increasing mass fraction of $\mathrm{TiB}_{2}$ in the specimen at an approximately constant density. 
and the chemical composition. A higher mass fraction of $\mathrm{TiB}_{2}$ in the specimen yields a higher value of $E$. When the mass fraction of $\mathrm{TiB}_{2}$ in the specimen exceeds $90 \%$, the value of the elastic modulus appears to converge to $565 \mathrm{GPa}$ at $23{ }^{\circ} \mathrm{C}$ as the density increases towards $4.5 \mathrm{~g} /$ $\mathrm{cm}^{3}$. At higher temperature $T$ the value of $E$ decreases as in Fig. 5 [22, 26, 30, 34-35], i.e., $\mathrm{d} E / \mathrm{d} T<0$. While the value of $E$ varies significantly with density and composition, the slope of $E$ vs $T$ is nearly constant with the mean value being $\mathrm{d} E / \mathrm{d} T=-(0.032 \pm 0.015) \mathrm{GPa} / \mathrm{K}$ for temperatures less than $1000{ }^{\circ} \mathrm{C}$. Consequently, for fully dense $\mathrm{TiB}_{2}$,

$$
E=E_{0}+(\mathrm{d} E / \mathrm{d} T)\left(T-T_{0}\right)
$$

where $296 \mathrm{~K} \leqslant T \leqslant 1273 \mathrm{~K}, \quad E_{0}=565 \mathrm{GPa}, \quad T_{0}=296 \mathrm{~K}$, and $u_{\mathrm{r}}(E)=5 \%$.

The shear modulus, shown in Fig. 5 [26, 30-31] for two different densities, also varies linearly from room temperature to $1000{ }^{\circ} \mathrm{C}$ with the average slope being $\mathrm{d} G / \mathrm{d} T=-(0.015 \pm 0.002) \mathrm{GPa} / \mathrm{K}$. Hence, for fully dense $\mathrm{TiB}_{2}$,

$$
G=G_{0}+(\mathrm{d} G / d T)\left(T-T_{0}\right),
$$

where $296 \mathrm{~K} \leqslant T \leqslant 1273 \mathrm{~K}, \quad G_{0}=255 \mathrm{GPa}, \quad T_{0}=296 \mathrm{~K}$, and $u_{\mathrm{r}}(G)=5 \%$.

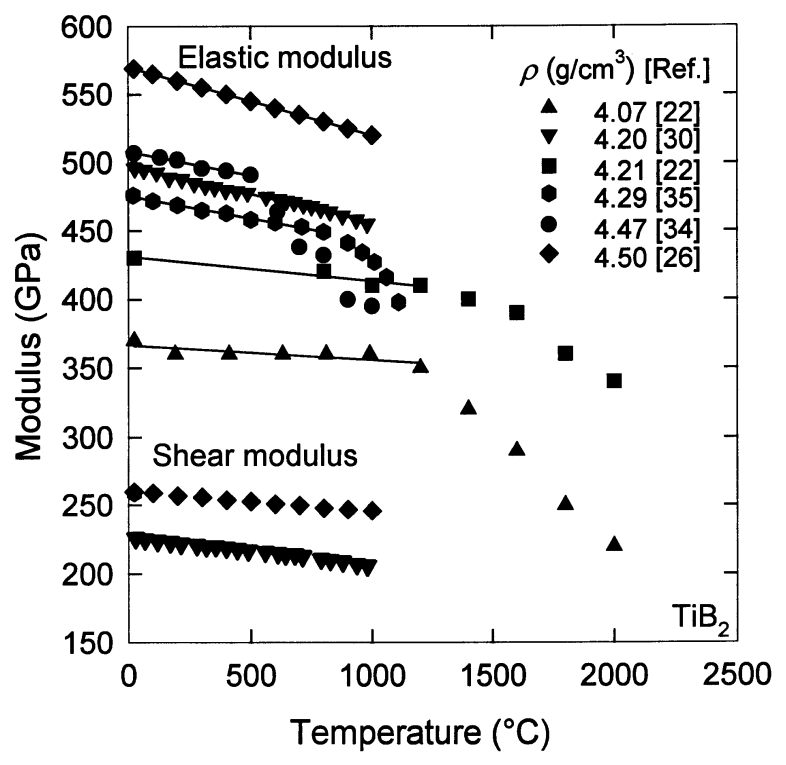

Fig. 5. The temperature dependence of the elastic and shear moduli of $\mathrm{TiB}_{2}$ for various densities.
Poisson's ratio $(v)$ and the bulk modulus $(B)$ can be calculated using the well known relations

$$
\begin{gathered}
v=\frac{E}{2 G}-1 \\
B=\frac{E \cdot G}{3(3 G-E)},
\end{gathered}
$$

which yield $v=0.11 \pm 0.08$ and $B=(240 \pm 57) \mathrm{GPa}$ for fully dense $\mathrm{TiB}_{2}$ at room temperature.

\subsection{Strength}

Proceeding from the results of the previous subsection, let us restrict our attention for the moment to specimens with a density of $(4.50 \pm 0.05) \mathrm{g} / \mathrm{cm}^{3}$ and consider the flexural strength $\sigma_{\mathrm{f}}$ of the material. A significant dependence on the grain size is readily seen in the results at room temperature shown in Fig. 6 [14, 22-24, 34, 36-37]. While this figure contains a mixture of data from three-point and four-point test methods using differing specimen sizes and crosshead speeds, the comparison clearly suggests that the strength $\sigma_{\mathrm{f}}$ decreases as the grain size increases. This result is at least consistent with reports that specimens prepared with grain size $\mathrm{g}>15 \mu \mathrm{m}$ exhibit spontaneous microcracking $[14,34,38]$ in the microstructure which would

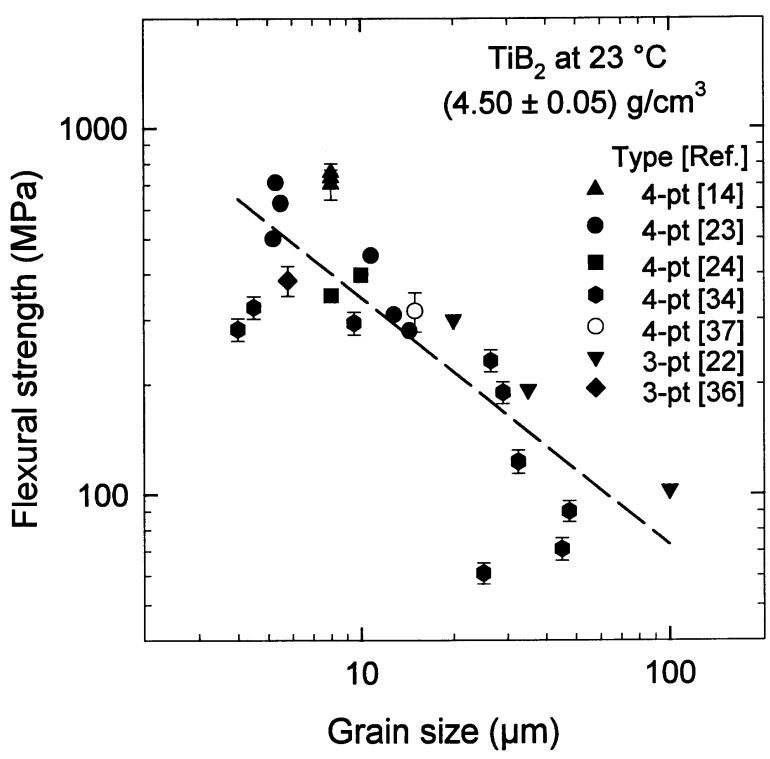

Fig. 6. Flexural strength $\sigma_{\mathrm{f}}$ of $\mathrm{TiB}_{2}$ at room temperature as a function of grain size for a fixed density. The dashed line is a least-squares fit. Error bars are the reported standard deviations. 
tend to reduce the strength of the material. At elevated temperature, the slope of $\sigma_{\mathrm{f}}$ with respect to $T$, Fig. 7 [22, $34,36]$, appears to be nearly constant for temperature less than $1500{ }^{\circ} \mathrm{C}$ and does not depend significantly on density, grain size, or test method. The average value of the slope is $\left(\partial \sigma_{\mathrm{f}} / \partial T\right)=(0.06 \pm 0.02) \mathrm{MPa} / \mathrm{K}$. Two effects have been suggested for the increase of strength with temperature. Strength may increase as a result of the relaxation of residual internal stresses produced in the specimens by the anisotropic thermal expansion of the microcrystalline constituent particles [34]. Crack healing due to oxidation and the formation of $\mathrm{B}_{2} \mathrm{O}_{3}$ may also contribute to this behavior for temperature up to about $1000{ }^{\circ} \mathrm{C}$, but room temperature strengths of specimens oxidized at higher temperatures appear to be diminished by oxidation [36].

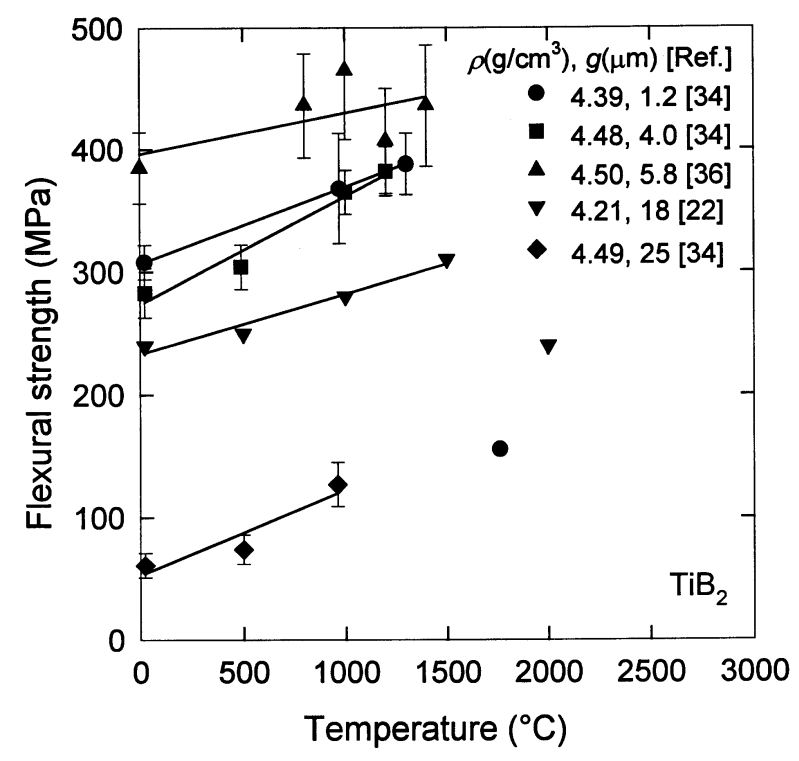

Fig. 7. The temperature dependence of the flexural strength of $\mathrm{TiB}_{2}$ in three-point bending for various densities and grain sizes. The lines are least-squares fits for temperature less than $1500{ }^{\circ} \mathrm{C}$. Error bars are the reported standard deviations.

In general, the fracture strength of a brittle material is limited by microstructural inhomgeneities, commonly called flaws. Every batch of brittle specimens has a distribution of flaw sizes which results in a distribution of measured strength values. For most structural ceramics, the Weibull distribution with two parameters provides an adequate description of the strength distribution. In this distribution, the Weibull modulus parameter $m$ provides an indication of the uniformity of the strength among the specimens. Higher values of $m$ im- ply a narrower distribution of strengths. Reliable determinations of the Weibull modulus, however, require the fracture of a relatively large number of specimens, at least 30 specimens according to the ASTM (American Society for Testing and Materials) standard test method C 1161 [39]. For $\mathrm{TiB}_{2}$, results for this number of specimens have rarely been reported in the current literature. The three values that may be cited here have significant differences: $m=11$ for a sintered material [24] with $\rho=4.55 \mathrm{~g} / \mathrm{cm}^{3}$ and $g=8 \mu \mathrm{m} ; m=29$ for a hot pressed material [24] with $\rho=4.51 \mathrm{~g} / \mathrm{cm}^{3}$ and $g=10 \mu \mathrm{m}$; and $m=8$ for a hot pressed material [37] with $\rho=4.48 \mathrm{~g} /$ $\mathrm{cm}^{3}$ and $g=15 \mu \mathrm{m}$.

Like most structural ceramics, $\mathrm{TiB}_{2}$ is considerably stronger under compression than in flexure or tension. The quantity of available data is very limited, and no two results were obtained by the same method. With that caution, it appears, at room temperature, that the dependence of compressive strength $\sigma_{\mathrm{c}}$ on density is approximately linear, ranging $[18,22]$ from $1.1 \mathrm{GPa}$ at $3.8 \mathrm{~g} /$ $\mathrm{cm}^{3}$ to $1.8 \mathrm{GPa}$ at $4.5 \mathrm{~g} / \mathrm{cm}^{3}$, when the grain size is $(18 \pm 3) \mu \mathrm{m}$. There also appears to be a significant dependence on the grain size, but the data set is limited to only one additional value [24], 5.7 GPa for a density of $4.51 \mathrm{~g} / \mathrm{cm}^{3}$ and a grain size of $10 \mu \mathrm{m}$.

\subsection{Fracture Toughness}

A clearer indication of the role of grain size in the optimization of the mechancial properties of $\mathrm{TiB}_{2}$ is provided by the fracture toughness as measured by the mode I critical stress intensity factor $K_{\text {Ic }}$. For fully dense specimens at room temperature, having a mass fraction of $\mathrm{TiB}_{2} \geqslant 98 \%$, Fig. $8[10,14-16,23-25,32,34,37$, 40-42], $K_{\text {Ic }}$ appears to have a maximum value for a mean grain size in the range $5 \mu \mathrm{m} \leqslant g \leqslant 12 \mu \mathrm{m}$. The values in Fig. 8 may be influenced by three potentially significant factors: grain size, measurement method, and chemical impurity content. A statistical factor analysis of these data indicates that $75 \%$ of the variability from the mean may be attributed to the variation of the mean grain size. The role of residual $\mathrm{Ni}$ impurities was considered explicitly in Ref. [14] and Ref. [23] where, neglecting the influence of grain size, it appeared that toughness increased with $\mathrm{Ni}$ content. However, taking into account the effect of grain size, the principal influence is seen to be microstructural rather than chemical. Combining this result with the observation in Fig. 6 that $g<10 \mu \mathrm{m}$ is needed to optimize $\sigma_{\mathrm{f}}$, the optimum grain size for $\mathrm{TiB}_{2}$ should be in the range $5 \mu \mathrm{m} \leqslant g \leqslant 10 \mu \mathrm{m}$. At the optimum, $K_{\mathrm{Ic}}=$ $(6.2 \pm 0.5) \mathrm{MPa} \cdot \mathrm{m}^{1 / 2}$. 
Journal of Research of the National Institute of Standards and Technology

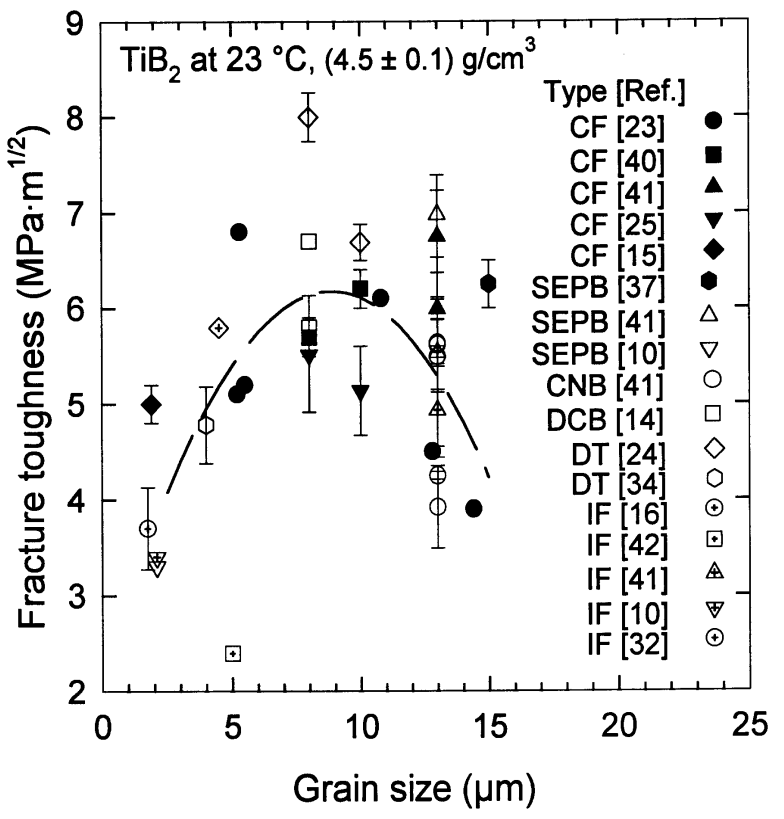

Fig. 8. Fracture toughness $K_{\mathrm{Ic}}$ of $\mathrm{TiB}_{2}$ at room temperature as a function of grain size for a fixed density. Error bars are the reported standard deviations.

\subsection{Hardness}

Given the manner in which strength and toughness depend on density and grain size, it might be expected that the plastic deformation of the material under indentation would also exhibit a dependence on density and grain size. It is somewhat surprising, therefore, that a cursory examination of the data for the Vickers hardness [43]

$$
H_{\mathrm{V}}=1.8544 \frac{P}{d^{2}}
$$

of $\mathrm{TiB}_{2}$ has no immediately perceptible dependence on either density or grain size $[10,14,15,17,42,44] . P$ is the applied load and $\mathrm{d}$ is the length of the diagonal of the indentation impression. However, there is a significant scatter in the data that appears to be principally a consequence of measurement differences, particularly the use of different indentation loads, as shown in Fig. 9. The data in Fig. 9 are consistent with the indentation size effect [45] according to which the size of the diagonal length of the indentation impression is related to the applied load; this relation is often assumed to be in the form of the Meyer law [46, 47] which is expressed as

$$
P=\zeta d^{\eta}
$$

where $\zeta$ and $\eta$ are parameters. Using a least-squares fit to the data in Fig. 9, it is easily found that $H \propto P^{-0.08}$,

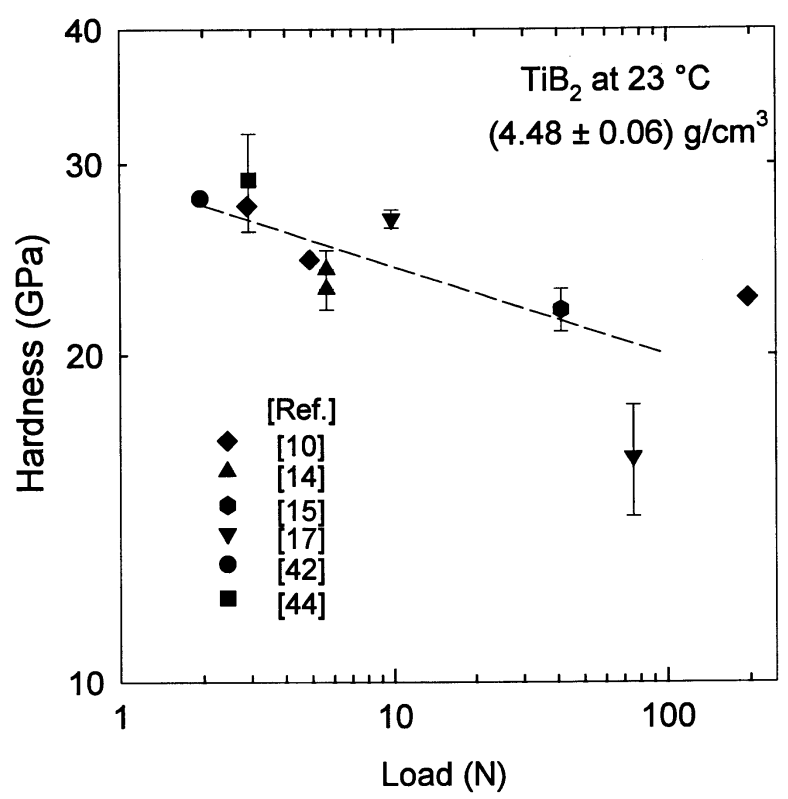

Fig. 9. Hardness of $\mathrm{TiB}_{2}$ at room temperature as a function of indentation load for a fixed density.

which corresponds to $\eta=1.85$. Consequently, to assess density and grain size effects on hardness, we must simultaneously resolve the load dependence of the observed values.

To evaluate the simultaneous effects of density, grain size, and load, let us consider an empirical expression

$$
H=h_{0}\left(\frac{\rho}{\rho_{0}}\right)^{h_{1}}\left(\frac{g}{g_{0}}\right)^{h_{2}}\left(\frac{P}{P_{0}}\right)^{h_{3}} \text {, }
$$

where the $h_{i}$ are adjustable parameters, and $\rho_{0}, g_{0}$, and $P_{0}$ are scale factors to make $h_{1}, h_{2}$, and $h_{3}$ dimensionless. Applying Eq. (10) to the room temperature data, taking $\rho_{0}=4.5 \mathrm{~g} / \mathrm{cm}^{3}, \quad g_{0}=10 \mu \mathrm{m}$, and $P_{0}=10 \mathrm{~N}$, yields $h_{0}=23 \mathrm{GPa}, h_{1}=-4.1, h_{2}=-0.034$, and $h_{3}=-0.072$, and the resulting fit has a relative uncertainty in the value of $H$ of only $9 \%$.

With the precaution that the value of $H$ depends on $\rho$, $g$, and $P$, the temperature dependence of the hardness [14] is shown in Fig. 10 for a load of $5.65 \mathrm{~N}$ and two conditions of density and grain size. As is often found for structural ceramics, $H_{\mathrm{V}}$ has an exponential dependence on temperature,

$$
H_{\mathrm{V}}=H_{0} \exp \left[-\left(T-T_{0}\right) / \tau\right]
$$

where $H_{0}, T_{0}$, and $\tau$ are parameters. Taking $T_{0}=296 \mathrm{~K}$, the value of $\tau$ can be found from Fig. 10 to be $\tau=580 \mathrm{~K}$. 


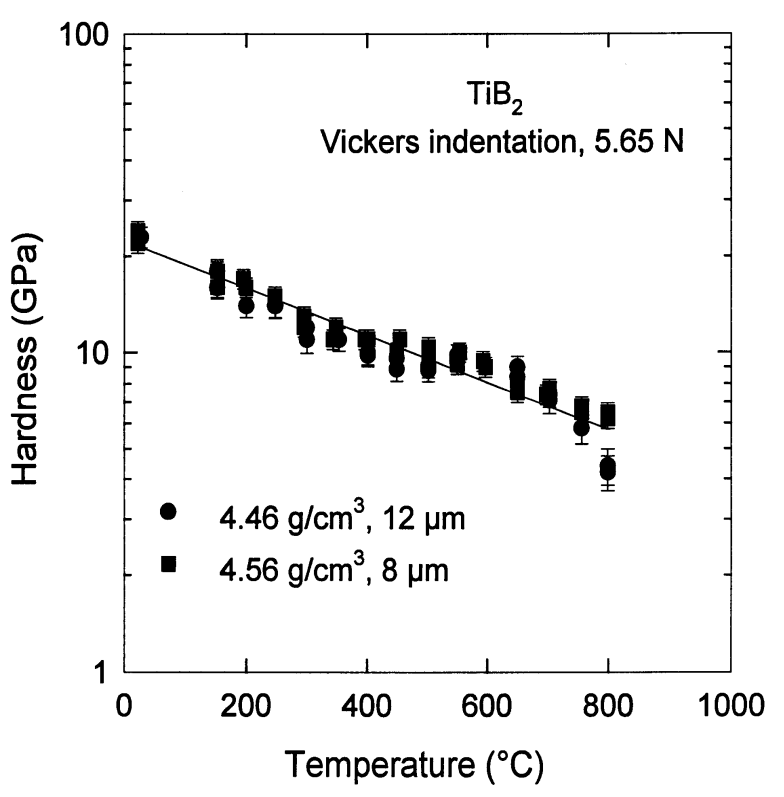

Fig. 10. The temperature dependence of the hardness of $\mathrm{TiB}_{2}$.

Using Eq. (10), the best estimate for $H_{0}$ with $\rho=4.5 \mathrm{~g} /$ $\mathrm{cm}^{3}, g=10 \mu \mathrm{m}$, and $P=5 \mathrm{~N}$ is $H_{0}=(24 \pm 2) \mathrm{GPa}$.

\subsection{Creep}

Deformation of a polycrystalline ceramic under sustained loading at high temperature produces creep, i.e., a strain that increases monotonically with time. A plot of strain vs time typically has three distinguishable regions denoted, respectively, as primary, secondary, and tertiary creep. While numerous mechanisms capable of producing creep have been identified [48], the principal mechanisms for creep in polycrystalline ceramics of high purity are thought to be solid state diffusional mechanisms. The secondary (also called steady-state) creep rate, $\mathrm{d} \epsilon / \mathrm{d} t$, for diffusional [49] and dislocation [50] mechanisms is often expressed in the form of the Norton model [51]

$$
\frac{\mathrm{d} \epsilon}{\mathrm{d} t}=A\left(\sigma / \sigma_{0}\right)^{n} \exp [-Q / R T]
$$

where the amplitude factor $A$, the stress exponent $n$, and the apparent activation energy $Q$ are adjustable parameters, $\sigma_{0}$ is a fixed scale factor that may be taken to be $1 \mathrm{MPa}$, and $R=8.31451 \mathrm{~J} \mathrm{~mol}^{-1} \mathrm{~K}^{-1}$ is the molar gas constant. This model is valid for specimens with a constant grain size if $\log (\mathrm{d} \epsilon / \mathrm{d} t)$ is linearly proportional to $1 / T$ and if the plots for various fixed values of the applied stress $\sigma$ are parallel. These conditions are satisfied approximately by the flexural creep data of $\mathrm{TiB}_{2}$
[22] as seen in Fig. 11. Applying Eq. (12) to these data, the parameters may be evaluated as $A=4.806 \times 10^{-4} \mathrm{~s}^{-1}$, $n=2.3$, and $Q=426 \mathrm{~kJ} / \mathrm{mol}$ for $\rho=4.29 \mathrm{~g} / \mathrm{cm}^{3}$ and $g=18 \mu \mathrm{m}$. With these parameters, the relative standard uncertainty of $\log (\mathrm{d} \epsilon / \mathrm{d} t)$ is $20 \%$ based on the statistical standard deviation of the fit.

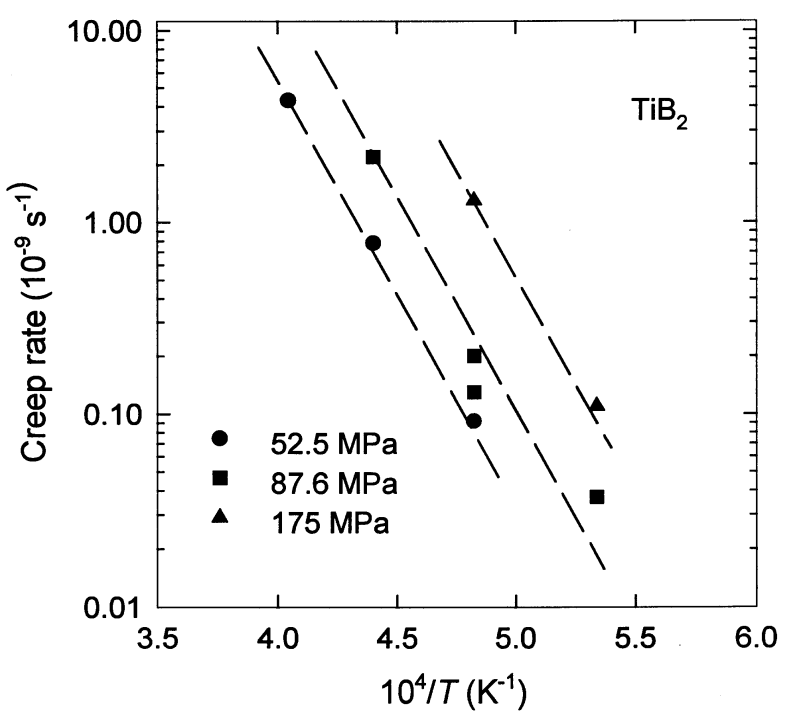

Fig. 11. Flexural creep rate of $\mathrm{TiB}_{2}$ as a function of inverse temperature for various values of applied stress. The dashed lines show the fit of Eq. (12).

\subsection{Friction and Wear}

Currently, one of the major uses of $\mathrm{TiB}_{2}$ is as a wear resistant material. For such applications, the friction and wear characteristics represent limiting benchmarks on the performance and durability of the material. In general, these characteristics are system properties, rather than material properties, and are functions of the temperature and loading conditions, the atmospheric and lubricating environments, the topological characteristics, and the relative sliding speed of the interacting surfaces [52]. However, in assessing the potential relative performance of materials in tribological applications, it is useful to know the friction and wear behavior of one specimen of the material sliding against another specimen of the same material in the absence of lubricating substances.

Even under such restricted conditions, the wear behavior of $\mathrm{TiB}_{2}$ is complicated by its interaction with oxygen in the atmosphere. Results from a ring on block test of the wear of $\mathrm{TiB}_{2}$ are shown in Fig. 12 [53] for a density of $4.32 \mathrm{~g} / \mathrm{cm}^{3}$ and a grain size of $2 \mu \mathrm{m}$. For temperature less than $600{ }^{\circ} \mathrm{C}$, the amount of material removed during the test increases with increasing 


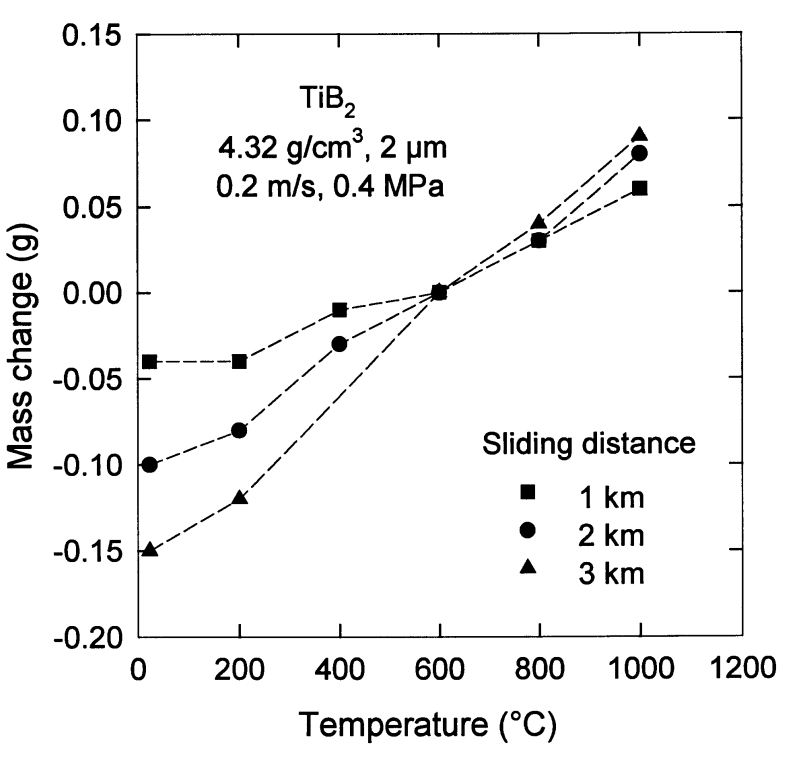

Fig. 12. Wear results for $\mathrm{TiB}_{2}$ from a ring on block test as a function of temperature for various sliding distances with fixed values of the density, grain size, sliding speed, and applied load.

sliding distance, but decreases with increasing temperature. For temperature greater than $600{ }^{\circ} \mathrm{C}$, the specimens gain mass with the amount of mass gain increasing with increasing sliding distance. The decrease of mass loss and the occurence of mass gain appear to be the result of the formation of $\mathrm{B}_{2} \mathrm{O}_{3}$ in the wear track of the specimens.

The coefficient of friction [53, 54], Fig. 13, varies somewhat with temperature with an apparent minimum occurring for temperatures near $800^{\circ} \mathrm{C}$. The quantitative differences between the results of the two references are probably the result of different operating conditions in the two ring on block experiments. The coefficient of friction appears to have a power law dependence on the ratio of the sliding speed $v_{\mathrm{s}}$ and the contact stress $P_{\mathrm{c}}$, as seen in Fig. 14. At $800{ }^{\circ} \mathrm{C}$, the friction coefficient has a value of about 0.2 when $v_{\mathrm{s}} /$ $P_{\mathrm{c}} \approx 0.06$. In Ref. [54], the contact stresses were not reported, but the load was in the range of $0.25 \mathrm{~N}$ to $29.4 \mathrm{~N}$ ( $25 \mathrm{~g}$ to $3 \mathrm{~kg}$ ). Hence, for the reported specimen dimensions, the apparent contact stress was in the range $1.4 \mathrm{kPa}$ to $0.17 \mathrm{MPa}$, indicating that $v_{\mathrm{s}} / P_{\mathrm{c}}$ was in the range $(0.36$ to 0.003$) \mathrm{m} \cdot \mathrm{s}^{-1} \cdot \mathrm{MPa}^{-1}$, which is consistent with Fig. 14, though not conclusive. From Fig. 14, for $v_{\mathrm{s}} / P_{\mathrm{c}}=0.2 \mathrm{~m} \cdot \mathrm{s}^{-1} \cdot \mathrm{MPa}^{-1}$, the coefficient of friction may be taken to be $0.8 \pm 0.1$ for temperature less than or equal to $400{ }^{\circ} \mathrm{C}$ and $0.4 \pm 0.1$ for temperature in the range $800{ }^{\circ} \mathrm{C}$ to $1000{ }^{\circ} \mathrm{C}$.

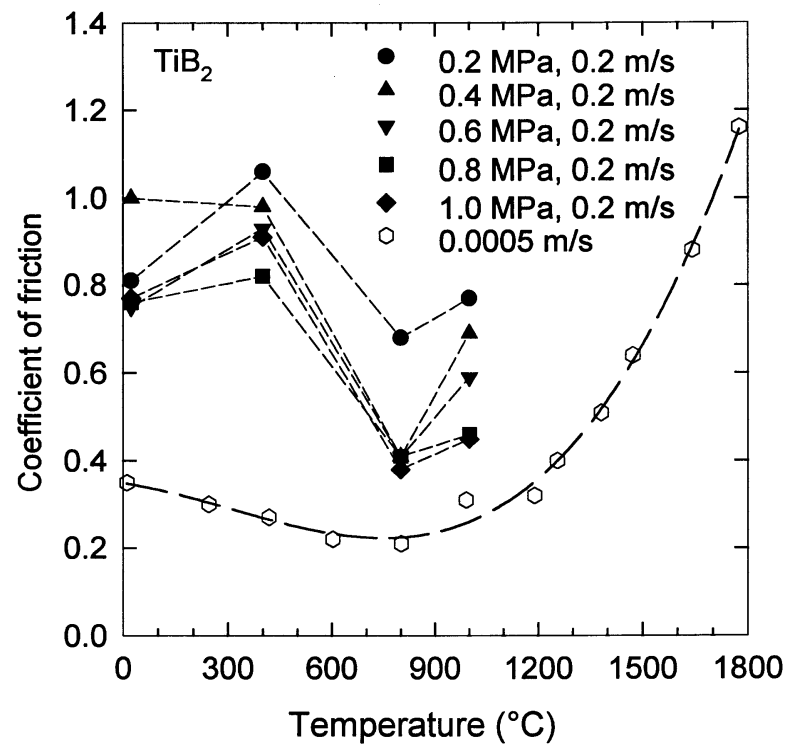

Fig. 13. Coefficient of friction of $\mathrm{TiB}_{2}$ from ring on block tests for sliding speeds of $0.2 \mathrm{~m} / \mathrm{s}$ (filled symbols, $\rho=4.32 \mathrm{~g} / \mathrm{cm}^{3}, g=2 \mu \mathrm{m}$ [53]) and $0.0005 \mathrm{~m} / \mathrm{s}$ (open symbols, density and contact stress are unknown, $g=0.7 \mu \mathrm{m}[54])$.

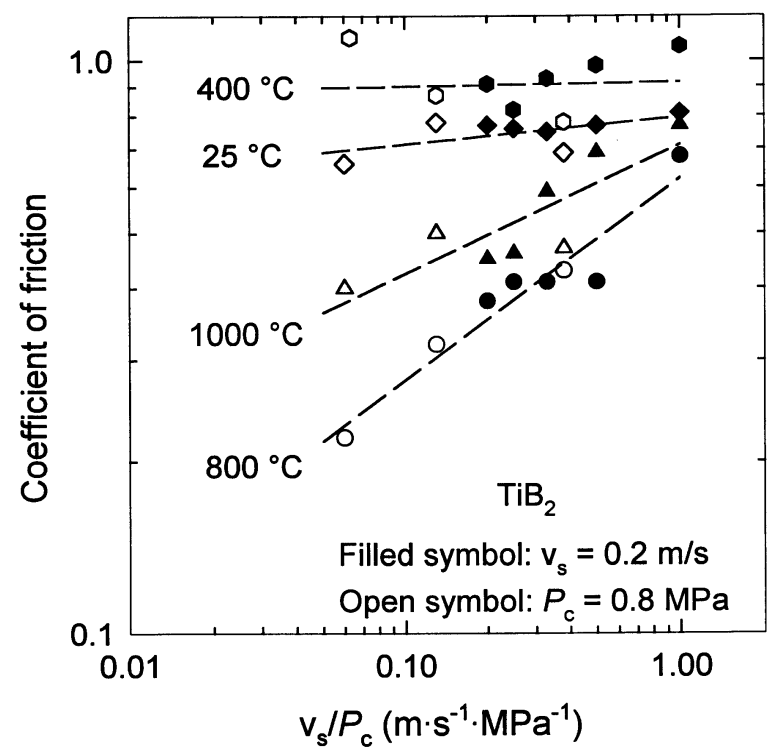

Fig. 14. Dependence of the coefficient of friction of $\mathrm{TiB}_{2}$ on the ratio of sliding speed and contact stress at various temperatures.

A further characteristic of the wear process is provided by the dimensionless wear coefficient [55]

$$
K_{\mathrm{W}}=\frac{V_{\mathrm{W}} H}{F_{\mathrm{n}} D_{\mathrm{s}}}
$$


where $V_{\mathrm{w}}$ is the wear volume, $H$ is hardness, $F_{\mathrm{n}}$ is the normal force acting between the surfaces, and $D_{\mathrm{s}}$ is the total sliding distance. For $\mathrm{TiB}_{2}$ at room temperature, $K_{\mathrm{w}}=(17 \pm 4) \times 10^{-4}$.

\subsection{Specific Heat}

There are several thermal properties that are important to most applications of ceramics at high temperature. The first of these is the specific heat, i.e., the amount of energy absorbed per unit mass to increase the temperature of the material by $1 \mathrm{~K}$. For specimens with relatively high purity and density, this quantity is rather insensitive to variations in grain size or the presence of the small amounts of impurities. As shown in Fig. 15 $[33,56]$, the specific heat of $\mathrm{TiB}_{2}$ increases monotonically with increasing temperature. The rapid rise at low

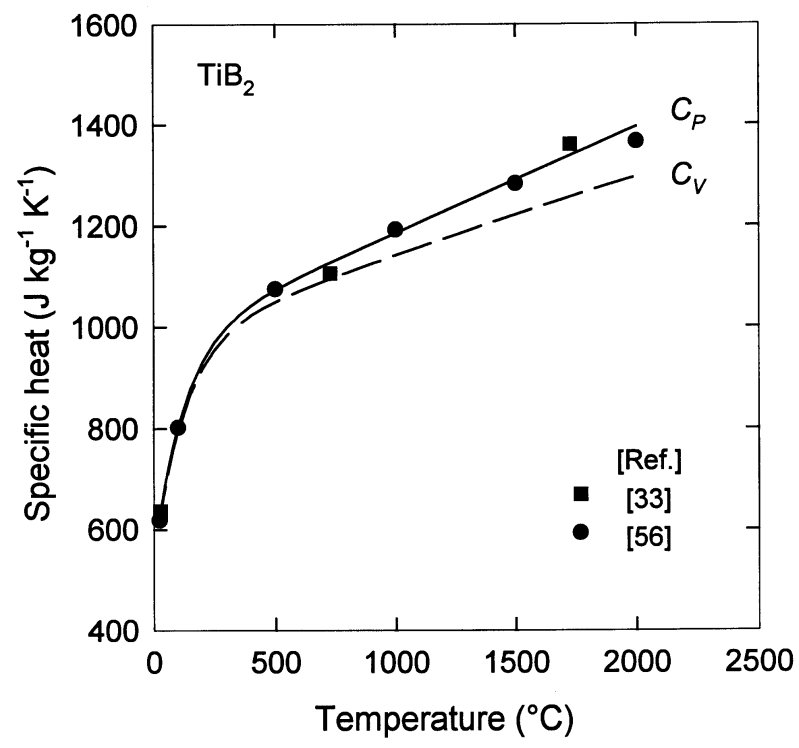

Fig. 15. Specific heat $C_{p}$ of $\mathrm{TiB}_{2}$ as a function of temperature. The solid curve is the fit of Eq. (14). The dashed curve is $C_{V}$ calculated from Eq. (15).

temperature and the linear variation at high temperature is readily fit by an interpolation formula of the form

$$
C_{p}=c_{0}+c_{1}(T / \mathrm{K}-273)+c_{2} \exp \left[-c_{3}(T / \mathrm{K}-273)\right] \text {, }
$$

where $C_{\mathrm{p}}$ is the specific heat at constant pressure, and the parameters are $c_{0}=976 \mathrm{~J} /(\mathrm{kgK}), c_{1}=0.21 \mathrm{~J} /(\mathrm{kgK})$, $c_{2}=-426 \mathrm{~J} /(\mathrm{kgK})$, and $c_{3}=0.008$ for $293 \mathrm{~K} \leqslant T \leqslant 2273 \mathrm{~K}$. The relative standard uncertainty of the specific heat when these parameters are used with Eq. (6) is $1.5 \%$ when the estimate of uncertainty is based on the standard deviation of the fit. Also shown in Fig. 15 is the specific heat at constant volume $C_{\mathrm{V}}$ which may be calculated from the thermodynamic relation

$$
C_{P}-C_{V}=T \rho^{-1} B \alpha_{V}^{2},
$$

where $\alpha_{\mathrm{V}}$ is the mean volumetric coefficient of thermal expansion (CTE). For isotropic materials, $\alpha_{\mathrm{V}}=3 \alpha_{\mathrm{m}}$, where $\alpha_{\mathrm{m}}$ is the mean linear CTE (Table 1 , footnote $\mathrm{h}$ ).

\subsection{Thermal Transport}

The transport of heat energy through the solid body of the material is described by two properties, thermal diffusivity $D$ and thermal conductivity $\kappa$. Thermal diffusivity pertains to transient heat flow, while thermal conductivity pertains to steady state heat flow. The two properties are related such that

$$
\kappa=\rho C_{P} D
$$

where $\rho$ and $C_{p}$ are the density and specific heat, respectively.

Data on the thermal transport properties of $\mathrm{TiB}_{2}$ are very scarce. Thermal diffusivity data [14] obtained using the laser flash technique are shown in Fig. 16 (open symbols) for two batches of $\mathrm{TiB}_{2}$. The higher density material with the smaller grain size also has a small nickel impurity (mass fraction of $0.43 \%$ ) which is not present in the other material. While it may be anticipated that these various factors may influence the diffusivity, there is insufficient data to discern any distinct effects at present. The diffusivity data can be converted to thermal conductivity data (filled symbols), using the results already given for density and specific heat. For each of these thermal transport properties, it is convenient to represent the values of the properties by an interpolation formula. For thermal diffusivity,

$$
D=D_{0}+\frac{D_{1} \exp \left[-D_{2}(T / \mathrm{K}-273)\right]}{D_{3}+(T / \mathrm{K}-273)}
$$

where the $D_{\mathrm{i}}$ are adjustable parameters. The dashed curve in Fig. 16 is given by Eq. (17) when $D_{0}=0.145 \mathrm{~cm}^{2} / \mathrm{s}, D_{1}=91.7 \mathrm{~cm}^{2} / \mathrm{s}, D_{2}=0.00279$, and $D_{3}=530$. For thermal conductivity,

$$
\kappa=\kappa_{0}+\frac{\kappa_{1} \exp \left[-\kappa_{2}(T / \mathrm{K}-273)\right]}{\kappa_{3}+(T / \mathrm{K}-273)},
$$

where the $\kappa_{i}$ are adjustable parameters. The solid curve in Fig. 16 is given by Eq. (18) when $\kappa_{0}=77.3 \mathrm{~W} \cdot \mathrm{m}^{-1} \cdot \mathrm{K}^{-1}, \kappa_{1}=8270 \mathrm{~W} \cdot \mathrm{m}^{-1} \cdot \mathrm{K}^{-1}$ $\kappa_{2}=0.002$, and $\kappa_{3}=410$. With these parameters, the relative standard uncertainty in the value of either $D$ or $\kappa$ is $6 \%$ in the temperature range $293 \mathrm{~K} \leq T \leq 1473 \mathrm{~K}$. 
Table 1. Mutually consistent trend values ${ }^{\mathrm{a}}$ for properties of polycrystalline $\mathrm{TiB}_{2}$ deduced from the collection of observed particular values for specimens having mass fraction of $\mathrm{TiB}_{2} \geqslant 98 \%, \rho=(4.5 \pm 0.1) \mathrm{g} / \mathrm{cm}^{3}$ and $g=(9 \pm 1) \mu \mathrm{m}$, except as noted

\begin{tabular}{|c|c|c|c|c|c|c|c|}
\hline \multirow[b]{2}{*}{ Property } & \multicolumn{7}{|c|}{ Temperature $\left({ }^{\circ} \mathrm{C}\right)$} \\
\hline & 20 & 500 & 1000 & 1200 & 1500 & 2000 & $u_{\mathrm{r}}^{\mathrm{b}}$ \\
\hline Bulk modulus (GPa) & 240 & 234 & 228 & & & & 24 \\
\hline Compressive strength (GPa) & 1.8 & & & & & & $?$ \\
\hline Creep rate ${ }^{\mathrm{c}}\left(10^{-9} \mathrm{~s}^{-1}\right)$ & & & & & 0.005 & 3.1 & 20 \\
\hline Density $^{\mathrm{d}}\left(\mathrm{g} / \mathrm{cm}^{3}\right)$ & 4.500 & 4.449 & 4.389 & 4.363 & 4.322 & 4.248 & 0.07 \\
\hline Elastic modulus (GPa) & 565 & 550 & 534 & & & & 5 \\
\hline Flexural strength (MPa) & 400 & 429 & 459 & 471 & 489 & & 25 \\
\hline Fracture toughness $\left(\mathrm{MPa} \cdot \mathrm{m}^{1 / 2}\right)$ & 6.2 & & & & & & 15 \\
\hline Friction coefficient $^{\mathrm{e}}$ & 0.9 & 0.9 & 0.6 & & & & 15 \\
\hline Hardness $(\mathrm{GPa})^{\mathrm{f}}$ & 25 & 11 & 4.6 & & & & 12 \\
\hline Lattice parameter ${ }^{\mathrm{d}} a / \AA$ & 3.029 & 3.039 & 3.052 & 3.057 & 3.066 & 3.082 & 0.03 \\
\hline Lattice parameter ${ }^{\mathrm{d}} c / \AA$ & 3.229 & 3.244 & 3.262 & 3.269 & 3.281 & 3.303 & 0.04 \\
\hline Poisson's ratio & 0.108 & 0.108 & 0.108 & & & & 70 \\
\hline Shear modulus (GPa) & 255 & 248 & 241 & & & & 5 \\
\hline Sound velocity, longitudinal ${ }^{\mathrm{g}}(\mathrm{km} / \mathrm{s})$ & 11.4 & 11.3 & 11.2 & & & & 5 \\
\hline Sound velocity, shear ${ }^{\mathrm{g}}(\mathrm{km} / \mathrm{s})$ & 7.53 & 7.47 & 7.40 & & & & 3 \\
\hline Specific heat $\left(\mathrm{J} \cdot \mathrm{kg}^{-1} \cdot \mathrm{K}^{-1}\right)$ & 617 & 1073 & 1186 & 1228 & 1291 & 1396 & 1.5 \\
\hline Thermal conductivity $\left(\mathrm{W} \cdot \mathrm{m}^{-1} \cdot \mathrm{K}^{-1}\right)$ & 96 & 81 & 78.1 & 77.8 & & & 6 \\
\hline Thermal diffusivity $\left(\mathrm{cm}^{2} / \mathrm{s}\right)$ & 0.30 & 0.17 & 0.149 & 0.147 & & & 6 \\
\hline Thermal expansion ${ }^{\mathrm{d}, \mathrm{h}} \alpha_{a}\left(10^{-6} \mathrm{~K}^{-1}\right)$ & 6.4 & 7.0 & 7.7 & 7.9 & 8.3 & 8.9 & 7 \\
\hline Thermal expansion $^{\mathrm{d}, \mathrm{h}} \alpha_{c}\left(10^{-6} \mathrm{~K}^{-1}\right)$ & 9.2 & 9.8 & 10.4 & 10.6 & 11.0 & 11.6 & 5 \\
\hline Thermal expansion $^{\mathrm{h}} \alpha_{\mathrm{m}}\left(10^{-6} \mathrm{~K}^{-1}\right)$ & 7.4 & 7.9 & 8.6 & 8.8 & 9.2 & 9.8 & 6 \\
\hline Wear coefficient ${ }^{\mathrm{e}}\left(10^{-3}\right)$ & 1.7 & & & & & & 24 \\
\hline Weibull modulus ${ }^{\mathrm{i}}$ & 11 & & & & & & $?$ \\
\hline
\end{tabular}

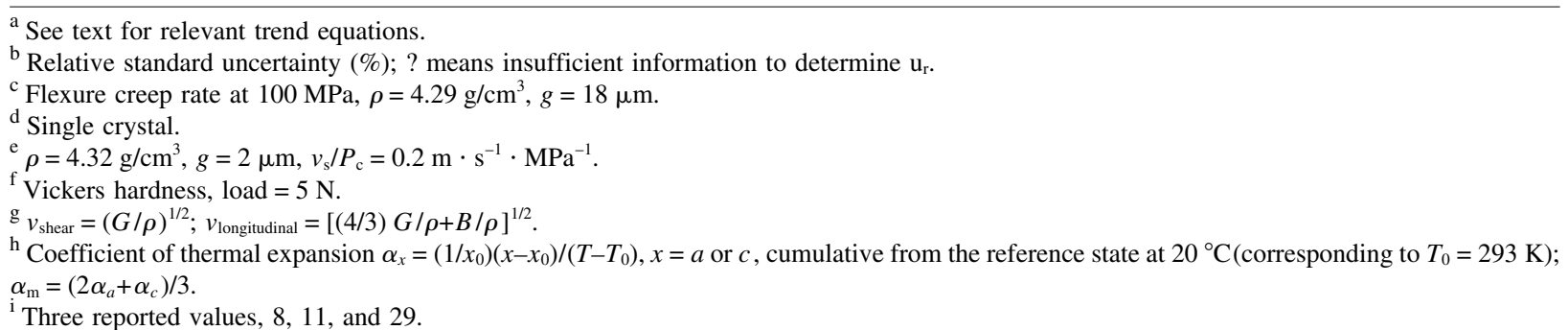

${ }^{\mathrm{i}}$ Three reported values, 8,11 , and 29.

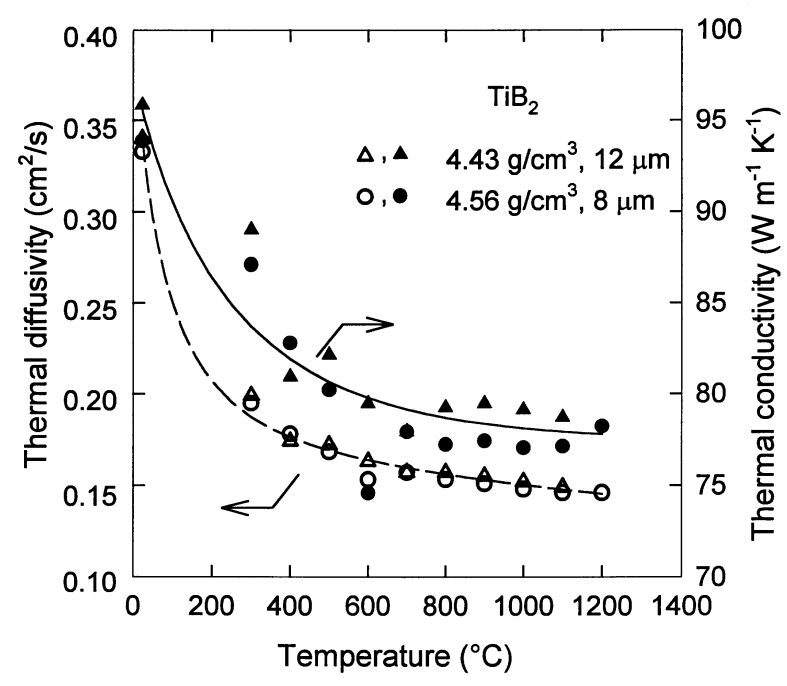

Fig. 16. Thermal diffusivity $\mathrm{D}$ and thermal conductivity $\kappa$ of $\mathrm{TiB}_{2}$ as a function of temperature. The dashed and solid curves are the fits of Eq. (17) and Eq. (18) respectively.

\section{Conclusion}

At the present time, there is no de facto production standard for $\mathrm{TiB}_{2}$, and consequently the variability of property values among different batches can be expected to be significant. However, trends in property values are related to the statistics of the microstructure, and that relation can be exploited to determine a consistent set of trend values for the properties of $\mathrm{TiB}_{2}$. Such trend values have been determined in the present work, Table 1 , focusing on a particular density, $\rho=$ $(4.5 \pm 0.1) \mathrm{g} / \mathrm{cm}^{3}$, and mean grain size, $g=(9 \pm 1) \mu \mathrm{m}$, as a function of temperature.

\section{References}

[1] V. I. Matkovich, Boron and Refractory Borides, Springer Verlag, New York (1977).

[2] R. G. Munro, Evaluated Material Properties for a Sintered

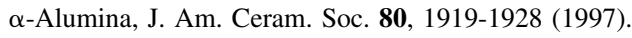

[3] R. G. Munro, Material Properties of a Sintered $\alpha-S i C$, J. Phys. Chem. Ref. Data 26, 1195-1203 (1997). 
[4] J. D. H. Donnay and H. M. Ondik, editors, Crystal Data Determinative Tables, II: Inorganic Compounds, Third Edition, Joint Committee on Powder Diffraction Standards (1973) pp. H-116 and $\mathrm{H}-117$.

[5] I. Higashi, Y. Takahashi, and T. Atoda, Crystal Growth of Borides and Carbides of Transition Metals from Molten Aluminum Solutions, J. Cryst. Growth 33, 207-211 (1976).

[6] B. Lonnberg, Thermal Expansion Studies on the Group IV-VII Transition Metal Diborides, J. Less-Com. Met. 141, 145-156 (1988).

[7] E. Fendler, O. Babushkin, T. Lindback, R. Telle, and G. Petzow, Thermal Expansion of Diboride Solid Solutions, in Fourth International Symposium on Ceramic Materials and Components for Engines, R. Carlsson, T. Johansson, and L. Kahlman, eds., Elsevier Applied Science, London and New York (1991) pp. 204-212.

[8] B. N. Taylor and C. E. Kuyatt, Guidelines for Evaluating and Expressing the Uncertainty of NIST Measurement Results, NIST Technical Note 1297, 1994 Edition, National Institute of Standards and Technology (1994).

[9] J. Matsushita, H. Nagashima, and H. Saito, Preparation and Mechanical Properties of $\mathrm{TiB}_{2}$ Composites Containing $\mathrm{Ni}$ and $\mathrm{C}$, J. Ceram. Soc. Jpn. 99, 78-82 (1991).

[10] S. Torizuka, H. Nishio, and T. Kishi, Sinterability and Mechanical Properties of $\mathrm{TiB}_{2}$ without Additives, J. Ceram. Soc. Jpn. 103, 1077-1081 (1995).

[11] S. Torizuka and T. Kishi, Effect of $\mathrm{SiC}$ and $\mathrm{ZrO}_{2}$ on Sinterability and Mechanical Properties of Titanium Nitride, Titanium Carbonitride, and Titanium Diboride, Mat. Trans., JIM 37, 782787 (1996).

[12] G. Suskin and G. I. Chepovetsky, Comparison of Vacuum and Pressure Assisted Sintering of $\mathrm{TiB}_{2}-\mathrm{Ni}$, J. Mat. Eng. Perf. 5, 396-398 (1996).

[13] M. Einarsrud, E. Hagen, G. Pettersen, and T. Grande, Pressureless Sintering of Titanium Diboride with Nickel, Nickel Boride, and Iron Additives, J. Am. Ceram. Soc. 80, 3013-3020 (1997).

[14] V. J. Tennery, C. B. Finch, C. S. Yust, and G. W. Clark, StructureProperty Correlations for $\mathrm{TiB}_{2}$-Based Ceramics Densified Using Active Liquid Metals, in Science of Hard Materials, R. K. Viswanadham, D. J. Rowcliffe, and J. Gurland, eds., Plenum, New York (1981) pp. 891-909.

[15] J. Besson, F. Valin, P. Lointier, and M. Boncoeur, Densification of Titanium Diboride by Hot Isostatic Pressing and Production of Near-Net-Shape Components, J. Mat. Eng. Perf. 1, 637-650 (1992).

[16] Y. Muraoka, M. Yoshinaka, K. Hirota, and O. Yamaguchi, Hot Isostatic Pressing of $\mathrm{TiB}_{2}-\mathrm{ZrO}_{2}\left(2 \mathrm{~mol} \% \mathrm{Y}_{2} \mathrm{O}_{3}\right)$ Composite Powders, Mat. Res. Bul. 31, 787-792 (1996).

[17] C. E. Holcombe and N. L. Dykes, Microwave Sintering of Titanium Diboride, J. Mat. Sci. 26, 3730-3738 (1991).

[18] L. Wang, M. R. Wixom, and L. T. Thompson, Structural and Mechanical Properties of $\mathrm{TiB}_{2}$ and TiC Prepared by Self-Propagating High-Temperature Synthesis/Dynamic Compaction, J. Mat. Sci. 29, 534-543 (1994).

[19] E. Rudy, Ternary Phase Equilibria in Transition Metal-BoronCarbon-Silicon Systems, Part V, Compendium of Phase Diagram Data, Technical Report AFML-TR-65-2, Part V, Wright-Patterson Air Force Base, Ohio (1969) p. 198.

[20] A. E. McHale, ed., Phase Equilibria Diagrams, Vol. X, Borides, Carbides, and Nitrides, American Ceramic Society (1994) pp. 140-141.
[21] H. Duschanek, P. Rogl, and H. L. Lukas, A Critical Assessment and Thermodynamic Calculation of the Boron-Carbon-Titanium (B-C-Ti) Ternary System, J. Phas. Eq. 16, 46-60 (1995).

[22] V. Mandorf, J. Hartwig, and E. J. Seldin, High Temperature Properties of Titanium Diboride, in High Temperature Materials II , G. M. Ault, W. F. Barclay, and H. P. Munger, eds., Gordon and Breach, New York (1963) pp. 455-467.

[23] P. F. Becher, C. B. Finch, and M. K. Ferber, Effect of Residual Nickel Content on the Grain Size Dependent Mechanical Properties of $\mathrm{TiB}_{2}$, J. Mat. Sci. Lett. 5, 195-197 (1986).

[24] C. Tracy, M. Slavin, and D. Viechnicki, Ceramic Fracture During Ballistic Impact, Adv. Ceram. 22, 295-306 (1988).

[25] C. A. Tracy and G. D. Quinn, Fracture Toughness by the Surface Crack in Flexure (SCF) Method, Ceram. Eng. Sci. Proc. 15 (5), 837-845 (1994).

[26] M. J. Pan, P. A. Hoffman, D. J. Green, and J. R. Hellmann, Elastic Properties and Microcracking Behavior of Particulate Titanium Diboride-Silicon Carbide Composites, J. Am. Ceram. Soc. 80, 692-698 (1997).

[27] R. M. Spriggs, Expression for Effect of Porosity on Elastic Modulus of Polycrystalline Refractory Materials, Particularly Aluminum Oxide, J. Am. Ceram. Soc. 44, 628-629 (1961).

[28] S. C. Nanjangud, R. Brezny, and D. J. Green, Strength and Young's Modulus Behavior of a Partially Sintered Porous Alumina, J. Am. Ceram. Soc. 78, 266-268 (1995).

[29] R. W. Rice, The Porosity Dependence of Physical Properties of Materials: A Summary Review, Key Eng. Mat. 115, 1-20 (1996).

[30] D. E. Wiley, W. R. Manning, and O. Hunter, Jr., Elastic Properties of Polycrystalline $\mathrm{TiB}_{2}, \mathrm{ZrB}_{2}$, and $\mathrm{HfB}_{2}$ from Room Temperature to $1400 \mathrm{~K}$, J. Less-Com. Met. 18, 149-157 (1969).

[31] P. S. Spoor, J. D. Maynard, M. J. Pan, D. J. Green, J. R. Hellmann, and T. Tanaka, Elastic Constants and Crystal Anisotropy of Titanium Diboride, Appl. Phys. Lett. 70, 19591961 (1997).

[32] M. K. Ferber, P. F. Becher, and C. B. Finch, Effect of Microstructure on the Properties of $\mathrm{TiB}_{2}$ Ceramics, J. Am. Ceram. Soc. 66, C-2-C-4 (1983).

[33] R. A. Cutler, Engineering Properties of Borides, in Engineered Materials Handbook, Vol. 4, Ceramics and Glasses, S. J. Schneider, Jr., ed., ASM International, Metals Park, Ohio (1991) pp. 787-803.

[34] H. R. Baumgartner and R. A. Steiger, Sintering and Properties of Titanium Diboride Made from Powder Synthesized in a PlasmaArc Heater, J. Am. Ceram. Soc. 67, 207-212 (1984).

[35] R. A. Andrievski and B. U. Asanov, Temperature Dependence of the Young's Modulus of the Composite $\mathrm{TiB}_{2}-\mathrm{Fe}$, J. Mat. Sci. Lett. 10, 147-148 (1991).

[36] J. Matsushita, T. Suzuki, and A. Sano, High Temperature Strength of $\mathrm{TiB}_{2}$ Ceramics, J. Ceram. Soc. Jpn. 101, 1074-1077 (1993).

[37] K. Cho, R. N. Katz, and I. Bar-On, Mechanical Properties of Hot Pressed Titanium Diboride, Army Research Laboratory Report ARL-TR-1185, National Technical Information Service, Washington, DC (1986).

[38] M. K. Ferber, P. F. Becher, and C. B. Finch, Effect of Microstructure on the Properties of $\mathrm{TiB}_{2}$ Ceramics, J. Am. Ceram. Soc. 66, C-2-C-4, (1983).

[39] Standard Test Method for Flexural Strength of Advanced Ceramics at Ambient Temperature, C 1161, 1997 Annual Book of ASTM Standards, Vol. 15.01, American Society for Testing and Materials, West Conshohocken, PA (1997). 
[40] H. Nayeb-Hashemi and C. A. Tracy, Microhardness Indentation Application and Limitation in Fracture-Toughness Evaluation of Ceramics, Exper. Mech. 31, 366-372 (1991).

[41] S. D. Conzone, W. R. Blumenthal, and J. R. Varner, Fracture Toughness of $\mathrm{TiB}_{2}$ and $\mathrm{B}_{4} \mathrm{C}$ Using the Single-Edge Precracked Beam, Indentation Strength, Chevron Notched Beam, and Indentation Strength Methods, J. Am. Ceram. Soc. 78, 2187-2192 (1995).

[42] H. Itoh, S. Naka, T. Matsudaira, and H. Hamamoto, Preparation of $\mathrm{TiB}_{2}$ Sintered Compacts by Hot Pressing, J. Mat. Sci. 25, 533-536 (1990).

[43] Standard Test Method for Microhardness of Materials, E 384, 1995 Annual Book of ASTM Standards, Vol. 03.01, American Society for Testing and Materials, Philadelphia, PA (1995).

[44] K. B. Shim, J. Kwiencinski, M. J. Edirisinghe, and B. Ralph, Microstructural Characterization of Titanium Diboride, Mat. Char. 31, 39-46 (1993).

[45] P. M. Sargent, Use of the Indentation Size Effect on Microhardness for Materials Characterization, in Microindentation Techniques in Materials Science and Engineering, ASTM STP 889, P. J. Blau and B. R. Lawn, eds., American Society for Testing and Materials, Philadelphia (1986) pp. 160-174.

[46] E. Meyer, Unterschugen über Prüfung and Härte, Zeitchrift des Vereines Deutcher Ingenieure 52, 645-654 (1908).

[47] B. W. Mott, Micro-Indentation Hardness Testing, Butterworths Scientific Publications, London (1956) pp. 101-107.

[48] A. Hynes and R. Doremus, Theories of Creep in Ceramics, Crit. Rev. Sol. St. Mat. Sci. 21 (2), 129-187 (1996).

[49] R. L. Coble, A Model for Boundary Diffusion Controlled Creep in Ceramic Materials, J. Appl. Phys. 34, 1679-1682 (1963).

[50] A. H.Chokshi and T. G. Langdon, Characteristics of Creep Deformation in Ceramics, Mat. Sci. Tech. 7, 577-584 (1991).

[51] F. H. Norton, The Creep of Steel at High Temperatures, McGraw Hill, New York (1929).

[52] F. P. Bowden and D. Tabor, The Friction and Lubrication of Solids, Clarendon, London, U.K. (1964) pp. 350-360.

[53] T. Senda, Y. Yamamoto, and Y. Ochi, Friction and Wear Test of Titanium Boride Ceramics at Elevated Temperatures, J. Ceram. Soc. Jpn. 101, 461-465 (1993).

[54] B. L. Mordike, The Frictional Properties of Carbides and Borides at High Temperatures, Wear 3, 374-387 (1960).

[55] E. Rabinowicz, New Coefficients Predict Wear of Metal Parts, Prod. Eng. 19, 71-73 (1958).

[56] M. E. Schlesinger, Melting Points, Crystallographic Transformation, and Thermodynamic Values, in Engineered Materials Handbook, Vol. 4, Ceramics and Glasses, S. J. Schneider, Jr., ed., ASM International, Metals Park, Ohio (1991) pp. 883-891.

About the author: Ronald G. Munro is a physicist in the NIST Ceramics Division of the Materials Science and Engineering Laboratory. The National Institute of Standards and Technology is an agency of the Technology Administration, U.S. Department of Commerce. 